\title{
Grafting Enhances Pepper Water Stress Tolerance by Improving Photosynthesis and Antioxidant Defense Systems
}

\author{
Yaiza Gara Padilla ${ }^{1}$ (), Ramón Gisbert-Mullor ${ }^{2}$ (), Lidia López-Serrano ${ }^{1}$, Salvador López-Galarza ${ }^{2}$ and \\ Ángeles Calatayud ${ }^{1, *}$ \\ 1 Centro de Citricultura y Producción Vegetal, Instituto Valenciano de Investigaciones Agrarias, Departamento \\ de Horticultura, CV-315, Km 10,7, Moncada, 46113 Valencia, Spain; padilla_yai@gva.es (Y.G.P.); \\ lopez_lid@gva.es (L.L.-S.) \\ 2 Departamento de Producción Vegetal, CVER, Universitat Politècnica de València, Camí de Vera s/n, \\ 46022 Valencia, Spain; ragismul@etsiamn.upv.es (R.G.-M.); slopez@upv.es (S.L.-G.) \\ * Correspondence: calatayud_ang@gva.es
}

check for

updates

Citation: Padilla, Y.G.;

Gisbert-Mullor, R.; López-Serrano, L.;

López-Galarza, S.; Calatayud, Á.

Grafting Enhances Pepper Water

Stress Tolerance by Improving

Photosynthesis and Antioxidant Defense Systems. Antioxidants 2021,

10, 576. https://doi.org/10.3390/

antiox10040576

Academic Editors:

Massimiliano Tattini and Lucia Guidi

Received: 27 January 2021

Accepted: 6 April 2021

Published: 8 April 2021

Publisher's Note: MDPI stays neutra with regard to jurisdictional claims in published maps and institutional affiliations.

Copyright: (c) 2021 by the authors. Licensee MDPI, Basel, Switzerland. This article is an open access article distributed under the terms and conditions of the Creative Commons Attribution (CC BY) license (https:/ / creativecommons.org/licenses/by/ $4.0 /)$.
Abstract: Currently, limited water supply is a major problem in many parts of the world. Grafting peppers onto adequate rootstocks is a sustainable technique used to cope with water scarcity in plants. For 1 month, this work compared grafted peppers by employing two rootstocks (H92 and H90), with different sensitivities to water stress, and ungrafted plants in biomass, photosynthesis, and antioxidant response terms to identify physiological-antioxidant pathways of water stress tolerance. Water stress significantly stunted growth in all the plant types, although tolerant grafted plants (variety grafted onto H92, Var/H92) had higher leaf area and fresh weight values. Var/H92 showed photosynthesis and stomata conductance maintenance, compared to sensitive grafted plants (Var/H90) and ungrafted plants under water stress, linked with greater instantaneous water use efficiency. The antioxidant system was effective in removing reactive oxygen species (ROS) that could damage photosynthesis; a significant positive and negative linear correlation was observed between the rate of $\mathrm{CO}_{2}$ uptake and ascorbic acid (AsA)/total AsA $\left(\mathrm{AsA}_{\mathrm{t}}\right)$ and proline, respectively. Moreover, in Var/H92 under water stress, both higher proline and ascorbate concentration were observed. Consequently, less membrane lipid peroxidation was quantified in Var/H92.

Keywords: Capsicum annuum; grafted plants; gas exchange; drought; oxidative stress; rootstock

\section{Introduction}

Abiotic stresses pose a huge threat for crops by limiting their growth and development, which eventually leads to poor productivity and low yields [1-3]. One abiotic stress is water limitation, which is considered a major problem because of its high intensity and time span, and because it causes significant crop losses worldwide every year [4-7]. Besides, many crops are now cultivated in areas where climate conditions are not always ideal, and precipitation may periodically go below optimal levels and lead to water scarcity [8].

Many kinds of approaches have been tested to deal with this threat, including agricultural practices focused on irrigation management, but also the introgression of drought resistance traits by molecular breeding. On the one hand, agricultural practices are not always suitable, given the peculiarities of each growing area and the unpredictability of drought periods. On the other hand, molecular and conventional breeding strategies have faced many difficulties when assessing drought tolerance because it is achieved by combining quantitative characters. These, in turn, are controlled by many minor genes with additive effects [2,4-6,9]. Alternatively, Genetically Modified plants have been developed, but these organisms are closely regulated and, like molecular breeding findings, they need to be validated in the field to prove their usefulness [10].

Given all these different approaches, vegetable grafting emerges as a sustainable effective technique, particularly in Solanaceae and Cucurbitaceae species, to overcome 
water deficit and other abiotic stresses by preventing harmful impacts on shoots [5,11-14]; because rootstock (root) performance stands out over scion (shoot) behavior when stress affects soil [15].

Several studies have confirmed positive physiological traits when employing tolerant rootstocks under water starvation conditions compared to ungrafted, self-grafted or plants grafted on susceptible rootstocks [16-20]. Photosynthesis is one of the first metabolic processes to be affected by drought [21,22]. Grafting has been identified as an effective tool for increasing $\mathrm{CO}_{2}$ assimilation and intrinsic water use efficiency ( $\left.A_{N} / E, W U E\right)[12,13]$ when tolerant rootstocks are employed. The increased WUE in tolerant grafted plants, compared to ungrafted plants or using sensitive rootstocks, is often related to a higher net $\mathrm{CO}_{2}$ assimilation rate and less transpiration, and is joined with stomata regulation [23-25]. However, a drop in WUE has also been observed in two tomato landraces grafted onto commercial tomato rootstocks, which has been associated with a more marked increase in stomatal conductance, linked with minor increases in net photosynthesis [26,27]. These differential WUE patterns indicate that WUE performance can depend not only on the rootstock, but also on the scion used, and mainly on water stress severity [28,29]. Generally with mild and moderate water stress, the decline in $\mathrm{A}_{\mathrm{N}}$ can be less severe than the drop in $\mathrm{g}_{\mathrm{s}}$, which causes WUE to increase. These results imply that stomatal limitations are responsible for reducing $A_{N}$ under drought stress, which is associated with a down-regulated photosynthetic metabolism [22,25,30]. Nevertheless, with severe water stress $A_{N}$ values drop more than $g_{s}$ values and, consequently, WUE usually lowers. This situation implies the existence of stomatal, but mainly non-stomatal limitations (inhibition of metabolic processes) connected with photosynthesis damage, which thus affects physiological adaptation to water stress $[18,22]$.

Maintaining photosynthesis under water limitation levels is essential because its suppression could increase excitation energy excess and electron flux to $\mathrm{O}_{2}$; which would result in photo-oxidative stress by reactive oxygen species (ROS) overproduction [31,32]. ROS damage proteins and nucleic acids by causing membrane dysfunction, followed by lipid peroxidation and enzymes inactivation [33]. ROS detoxification is most important in any defense mechanism, this is why plants possess a complex antioxidant system that includes non-enzymatic molecules (e.g., ascorbate, proline, phenols, tocopherols [34]), but also antioxidant enzymatic components (e.g., catalase, superoxide dismutase, peroxidase, and components of the ascorbate-glutathione cycle [35]).

Increasing antioxidant system activities is necessary to enhance plant protection and for reaching tolerance below non optimal water levels [8]. In recent years, more attention has been paid to understand the antioxidative system in plants under water deficit [36], but less research has been performed in grafted plants to identify potential antioxidative mechanisms of drought tolerance. These studies have been performed mainly in tomato, watermelon and cucumber grafted plants [5], with very few reports available on antioxidants regulation in pepper-grafted plants [16,20].

Pepper is one of the most important crops grown in the Mediterranean climate, where water scarcity is a relevant constraint [16]. Nevertheless, commercial rootstocks are not usually employed in pepper plants as they do not provide enough benefits $[37,38]$.

Our previous studies performed classical breeding assays with pepper accessions (C. annuum $\times$ C. annuum) that resulted in hybrids with more uniform germination, vigor, and growth. These hybrids were tested and screened under water stress conditions based on photosynthetic parameters, leading to identify both tolerant and sensitive hybrids under water stress (unpublished data). Of these, one tolerant rootstock (H92) with higher $\mathrm{CO}_{2}$ assimilation and one sensitive rootstock (H90) were chosen to test the hypothesis herein posed.

The aim of the present study is to determine whether the maintenance of photosynthesis observed in the tolerant hybrid rootstock (H92) under water stress is associated with the protection of the photosynthetic apparatus, mediated by the activation of the antioxidant system components. For this purpose, several parameters, such as biomass, photosynthetic 
parameters, ascorbate, proline, catalase activity, and lipid peroxidation were determined in grafted plants using tolerant and sensitive rootstocks and ungrafted plants, grown both in water stress and control conditions.

\section{Materials and Methods}

\subsection{Plant Material}

Two Capsicum annuum hybrids (codes H92 and H90, tolerant and sensitive to water stress, respectively), obtained through traditional breeding by crossing pepper accessions in previous studies [39-41], were selected from a pool of 11 hybrids to be used as rootstocks in the present study. Pepper landrace "Sueca" (Var) was employed as scion and as ungrafted plants. Seeds were sown in March 2020 in 104-hole trays with enriched substrate under greenhouse conditions. Two months after germination, Var was grafted by the tubegrafting method onto the studied hybrid rootstocks. Three weeks after grafting, plants were transplanted in 6-L pots with coconut coir fiber (Cocopeat, Projar Co., Valencia, Spain) in a polyethylene greenhouse at the Valencian Institute of Agriculture Research (IVIA; Valencia, Spain). During the experimental period, temperature ranged from $20{ }^{\circ} \mathrm{C}$ to $30{ }^{\circ} \mathrm{C}$, with $40-80 \%$ relative humidity $(\mathrm{RH})$. Twelve plants per plant combination were used.

After allowing pepper plants to adapt to the greenhouse for 1 week, they were distributed for two treatments (six plants per treatment). Under the water stress conditions, water irrigation was lowered to $55 \%$ of total irrigation under the control conditions, which was calculated based on the weekly crop evapotranspiration (ETc). The number of irrigations was scheduled to maintain drainage between $20 \%$ and $30 \%$. Plants were irrigated with Hoagland's no. 2 nutrient solution containing (all in $\mathrm{mM}$ ): $14 \mathrm{NO}_{3}{ }^{-}, 1.0 \mathrm{H}_{2} \mathrm{PO}_{4}{ }^{-}$, $2.0 \mathrm{SO}_{4}{ }^{2-}, 1.0 \mathrm{NH}_{4}{ }^{+}, 6.0 \mathrm{~K}^{+}, 4.0 \mathrm{Ca}^{2+}$, and $2.0 \mathrm{Mg}^{2+}$. Micronutrients were also provided (all in $\mu \mathrm{M}$ ): $15 \mathrm{Fe}^{2+}, 10 \mathrm{Mn}^{2+}, 5 \mathrm{Zn}^{2+}, 30 \mathrm{~B}^{3+}, 0.75 \mathrm{Cu}^{2+}$, and $0.6 \mathrm{Mo}^{6+}$ ) [42]. Electrical conductivity was $1.9 \mathrm{dSm}^{-1}$ and $\mathrm{pH}$ was 6.7 . To apply the same fertilizer doses in the control and water stress treatments, nutrient solution was applied to both treatments when irrigation to stressed plants was administered. To meet irrigation water requirements, only water was applied to the other irrigation events in the non-stressed treatment.

All of the measurements were taken 10 days after treatment (10 DAT) started, 20 DAT, and 30 DAT. During each measurement event, four measurements (one plant/replication) per plant type and treatment combination were taken. Photosynthetic parameters and physiological analyses were measured on the third or fourth leaves from the apex. For the physiological analysis, leaves were previously frozen with liquid nitrogen and stored at $-80^{\circ} \mathrm{C}$. Samples were ground by a mixer mill (MM400, Retsch, Hann, Germany) with liquid nitrogen to prevent melting.

\subsection{Water Relations}

Osmotic potential of leaf sap ( $\Psi$ s, in $\mathrm{MPa}$ ) and relative water content (RWC) were measured at 30 DAT in leaves. RWC was determined by weighing leaves before and after a $24 \mathrm{~h}$ rehydration process performed with distilled water, obtaining the fresh weigh (FW) and turgid weight (TW), respectively. To obtain the dry weight (DW), leaves were dried at $65^{\circ} \mathrm{C}$ for $72 \mathrm{~h}$ and then weighed. RWC was determined as: RWC $(\%)=(F W-D W) /(T W-D W) \times 100$.

The $\Psi$ s was measured by an osmometer (Digital Osmometer, Wescor, Logan, UT, USA). Leaves were detached, placed inside $1 \mathrm{~mL}$ tubes, and quickly frozen at $-20^{\circ} \mathrm{C}$. After melting, sap was collected by centrifugation for $1 \mathrm{~min}$ at $9.000 \mathrm{rpm}$ in $1.5 \mathrm{~mL}$ tubes. Osmolyte content of leaf sap (mmol kg-1) was converted into MPa by the Van't Hoff equation [18].

\subsection{Gas Exchange Measurements}

The $\mathrm{CO}_{2}$ assimilation rate $\left(\mathrm{A}_{\mathrm{N}}, \mu \mathrm{mol} \mathrm{CO} \mathrm{m}^{-2} \mathrm{~s}^{-1}\right)$, stomatal conductance to water vapor $\left(g_{s}\right.$, mol H $\left.\mathrm{O} \mathrm{m}^{-2} \mathrm{~s}^{-1}\right)$, substomatal $\mathrm{CO}_{2}$ concentration $\left(\mathrm{C}_{\mathrm{i}}, \mu \mathrm{mol} \mathrm{CO} \mathrm{CO}_{2} \mathrm{~mol}^{-1}\right.$ air $)$ and transpiration rate $\left(\mathrm{E}, \mathrm{mmol} \mathrm{H} \mathrm{O} \mathrm{m}^{-2} \mathrm{~s}^{-1}\right)$ were measured by a portable LI-COR 6400 infrared gas analyzer (Li-Cor Inc., Lincoln, NE, USA). The $\mathrm{A}_{\mathrm{N}} / \mathrm{E}$ parameter was calculated as instantaneous WUE. Measurements were taken under saturating light conditions 
(1000 $\mu \mathrm{mol}$ quanta $\left.\mathrm{m}^{-2} \mathrm{~s}^{-1}\right), 400 \mu \mathrm{mol} \mathrm{CO} \mathrm{Col}^{-1}$ of reference $\mathrm{CO}_{2}$, at $27^{\circ} \mathrm{C}\left(27 \pm 2{ }^{\circ} \mathrm{C}\right)$ and $75 \% \mathrm{RH}$. For each measurement time, data were collected on two consecutive days from 09:00 h to 11:00 $\mathrm{h}(\mathrm{UT}+$ 01:00 $\mathrm{h})$.

\subsection{Ascorbate Metabolism}

Ascorbic acid (AsA), dehydroascorbate (DHA) and total AsA (AsA $A_{t}=$ AsA + DHA) were determined in parallel according to [43] with some variations. First $0.4 \mathrm{~g}$ of sample was mixed with $80 \%(w / v)$ trichloroacetic acid (TCA) and centrifuged for $5 \mathrm{~min}$ at $15,000 \times g$ and $4{ }^{\circ} \mathrm{C}$. Then $50 \mu \mathrm{L}$ of the supernatant were mixed with $150 \mu \mathrm{L}$ of $0.2 \mathrm{M}$ phosphate buffer ( $\mathrm{pH}$ 7.4) and $50 \mu \mathrm{L}$ of distilled $\mathrm{H}_{2} \mathrm{O}_{2}$ for the AsA determination. For AsA $\mathrm{A}_{\mathrm{t}}, 50 \mu \mathrm{L}$ of the supernatant were mixed with $50 \mu \mathrm{L}$ of $10 \mathrm{mM}$ dithiothreitol (DTT) and $100 \mu \mathrm{L}$ of $0.2 \mathrm{M}$ phosphate buffer ( $\mathrm{pH} 7.4$ ), and incubated in a water bath at $42{ }^{\circ} \mathrm{C}$ for $15 \mathrm{~min}$. Then $50 \mu \mathrm{L}$ of $0.5 \%(w / v)$ N-ethylmaleimide (NEM) were added and samples were incubated for $1 \mathrm{~min}$ at room temperature. Both AsA and $\mathrm{AsA}_{t}$ tubes were mixed with $250 \mu \mathrm{L}$ of $10 \%(w / v)$ TCA, $200 \mu \mathrm{L}$ of $42 \%(v / v) \mathrm{H}_{3} \mathrm{PO}_{4}, 200 \mu \mathrm{L}$ of $4 \%(w / v) 2,2$-dipyridyl and $100 \mu \mathrm{L}$ of $3 \%(w / v) \mathrm{FeCl}_{3}$, and incubated in a water bath for $40 \mathrm{~min}$ at $42{ }^{\circ} \mathrm{C}$. Absorbance was recorded at $525 \mathrm{~nm}$ in both cases. The DHA concentration was determined as: AsA $_{t}-$ AsA.

\subsection{Catalase Activity}

Catalase enzyme activity (EC 1.11.1.6) was measured as in [44], but with modifications: $0.5 \mathrm{~g}$ of the sample was mixed with $2.5 \mathrm{~mL}$ of $10 \mathrm{mM}$ potassium phosphate buffer (with $1.27 \mathrm{mM}$ EDTA and $\mathrm{pH} 7)$ and $2.5 \%(w / v)$ polyvinylpolypyrrolidone (PVPP), and was centrifuged for $30 \mathrm{~min}$ at $10,000 \times g$ and $4{ }^{\circ} \mathrm{C}$. The supernatant was conserved under ice conditions until measurements were taken. To start the reaction, $1960 \mu \mathrm{L}$ of $50 \mathrm{mM}$ potassium phosphate (pH 7) were mixed with $20 \mu \mathrm{L}$ of sample and $20 \mu \mathrm{L}$ of $\mathrm{H}_{2} \mathrm{O}_{2}$. Reduction of $\mathrm{H}_{2} \mathrm{O}_{2}$ by catalase activity was monitored spectrophotometrically at $240 \mathrm{~nm}$ for $4 \mathrm{~min}$ at room temperature. $\mathrm{U}(\mu \mathrm{mol} / \mathrm{min}) \mathrm{g}^{-1} \mathrm{FW}$ was calculated using the Lambert-Beer equation with the $\mathrm{H}_{2} \mathrm{O}_{2}$ extinction coefficient $\left(\varepsilon=39.4 \mathrm{mM}^{-1} \mathrm{~cm}^{-1}\right)$.

\subsection{Lipid Peroxidation Analysis}

Lipid peroxidation was determined by the malondialdehyde (MDA) procedure using the thiobarbituric acid (TBA) reaction according to [45], and modified by [46]: $0.1 \mathrm{~g}$ of sample was mixed with $2 \mathrm{~mL}$ of $0.1 \%(w / v)$ TCA and centrifuged for $5 \mathrm{~min}$ at $10,000 \times g$ and $4{ }^{\circ} \mathrm{C}$. Later, $1 \mathrm{~mL}$ of supernatant was mixed with $2 \mathrm{~mL}$ of reaction buffer $(20 \% \mathrm{TCA}+0.5 \%$ TBA) and samples were incubated for $30 \mathrm{~min}$ at $95^{\circ} \mathrm{C}$ in a water bath. The non-specific background absorbance reading at $600 \mathrm{~nm}$ was subtracted from the specific absorbance reading at $532 \mathrm{~nm}$.

\subsection{Proline Determination}

Proline quantification was performed as reported in [47] with slight differences: $0.2 \mathrm{~g}$ of the sample was mixed with $1.5 \mathrm{~mL}$ of $3 \%$ sulfosalicylic acid and centrifuged for $5 \mathrm{~min}$ at $14,000 \mathrm{rpm}$ and room temperature. Next, $0.6 \mathrm{~mL}$ of glacial acetic acid and $0.7 \mathrm{~mL}$ of ninhydrin reagent $(40 \mathrm{~mL}$ of $6 \mathrm{M}$ phosphoric acid mixed with $2.5 \mathrm{~g}$ ninhydrin previously blended in $600 \mathrm{~mL}$ of glacial acetic acid) were added to $70 \mu \mathrm{L}$ of the supernatant, and samples were heated for $1 \mathrm{~h}$ at $100{ }^{\circ} \mathrm{C}$. Absorbance measures were taken at $520 \mathrm{~nm}$ and interpolated on a standard curve performed with proline.

\subsection{Plant Biomass and Leaf Area Determination}

The biomass parameters were measured at the end of the experiment (30 DAT). Leaves and stems were weighed and the number of leaves per plant was recorded. The total leaf area was measured with a LI-3100 Area Meter (Li-COR Inc., Lincoln, NE, USA). Later leaves and stems were exposed to dry heat (for $72 \mathrm{~h}$ at $70{ }^{\circ} \mathrm{C}$ ) in a laboratory oven and dry weight (DW) was recorded. 


\subsection{Statistical Analysis}

The results of all the parameters were subjected to a two-way analysis of variance (ANOVA) with Statgraphics Centurion 18 (Statgraphics Technologies Inc., The Plains, VA, USA) after including two factors, namely plant type (PT) and treatment (T), and by considering their interaction. The physiological parameters were analyzed separately for each measurement time (10, 20, and $30 \mathrm{DAT})$. The means of all the parameters were compared by Fisher's least significance difference (LSD test) at $p<0.05$. No significant differences were found in the replicates for each measured parameter. The correlation analyses between $\mathrm{A}_{\mathrm{N}}$ and $\mathrm{AsA} / \mathrm{AsA}_{t}$ and $\mathrm{A}_{\mathrm{N}}$ and proline were performed with the abovementioned Statgraphics software and the correlation coefficient $(r)$ was obtained.

\section{Results}

\subsection{Water Relations}

Leaf RWC values (Figure 1A) showed significant interaction between PT and T $(p<0.01)$. Plants under control conditions maintained RWC between 90 and $100 \%$ at the end of the experiment without significant differences among them. Water stress reduced significantly the RWC in all PT. Var plants were the most sensitive (77\% RWC) followed by Var/H90 (83\%) and Var/H92 (86\%).
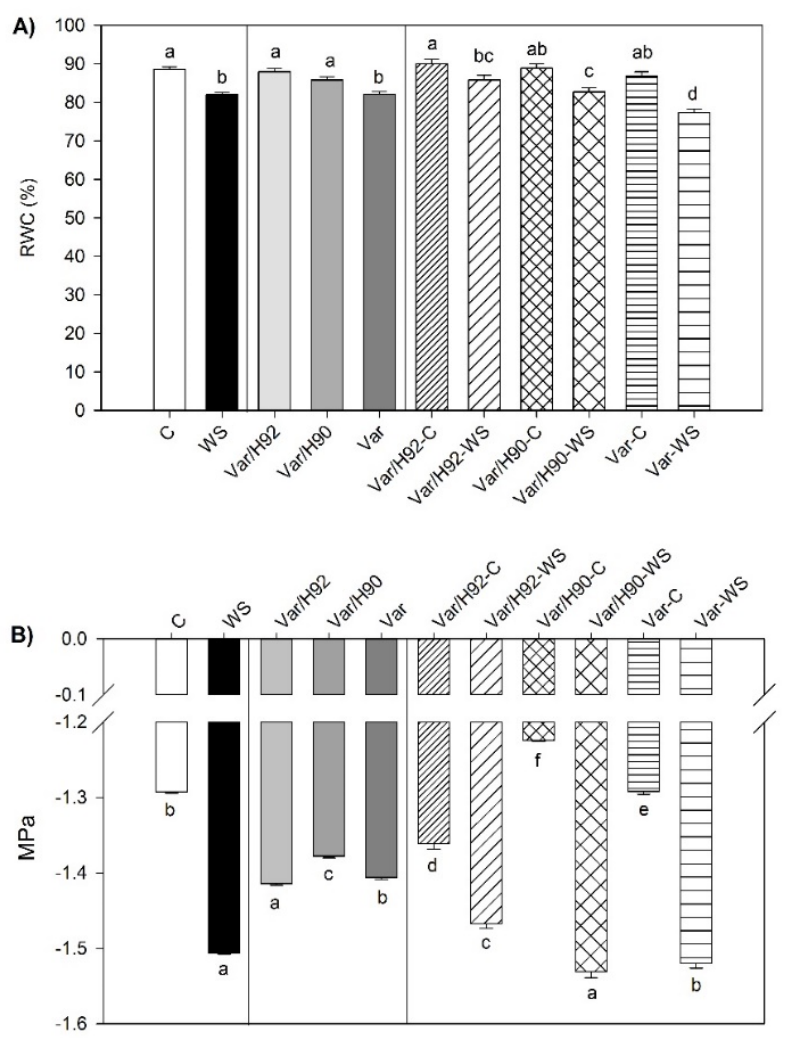

Figure 1. (A) Relative water content (RWC) and (B) osmotic potential ( $\Psi$ s) in leaves for the ungrafted plants (Var, variety "Sueca") and Var grafted onto H92 or H90 (Var/H92 and Var/H90, respectively) under the water stress (WS) or control conditions (C). Measurements were taken at 30 DAT (days after treatment). Data are the mean of four replicates and the error bars belong to the standard deviation for each plant type and treatment combination. Different letters indicate significant differences at $p<0.05$ (least significance difference (LSD) test).

Leaf osmotic potential ( $\Psi$ s) values at 30 DAT are showed in Figure 1B. Significant interaction was observed $(\mathrm{PT} \times \mathrm{T})$ with $p<0.01$. Under WS, all PT showed significant lower values compared to control conditions; Var/H90 displayed the largest decrease and Var/H92 the lowest drop in $\Psi$ s with significant differences among them. 


\subsection{Gas Exchange Measurements}

All the measured photosynthetic parameters (except $g_{s}$ at 30 DAT and $A_{N} / E$ at 20 DAT) exhibited a statistically significant interaction between treatment (T) and plant type (PT). For this interaction, $\mathrm{A}_{\mathrm{N}}$ at $30 \mathrm{DAT}$, and $\mathrm{g}_{\mathrm{s}}$ at $10 \mathrm{DAT}$ presented $p<0.05$, with $p<0.01$ for the remaining photosynthetic parameters and DAT.

The leaf $\mathrm{CO}_{2}$ assimilation rate $\left(\mathrm{A}_{\mathrm{N}}\right.$, Figure $\left.2 \mathrm{~A}\right)$ significantly lowered under water stress for the variety grafted onto $\mathrm{H} 90$ (Var/H90) and the ungrafted variety (Var) throughout the experiment. The variety grafted onto H92 (Var/H92) only displayed significant differences when comparing the control and water stress plants at the end of the experiment (30 DAT).

A)

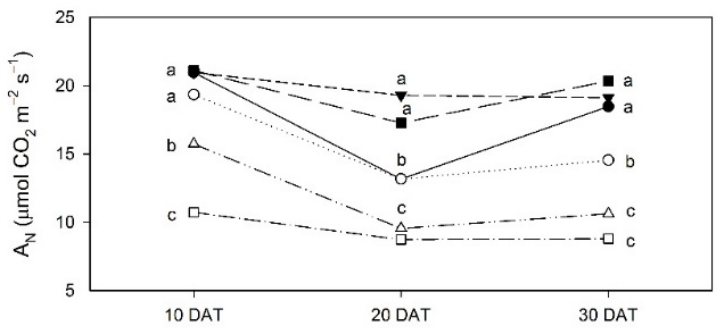

B)

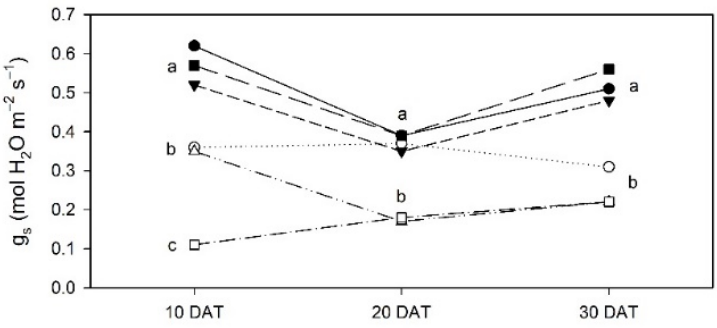

C)

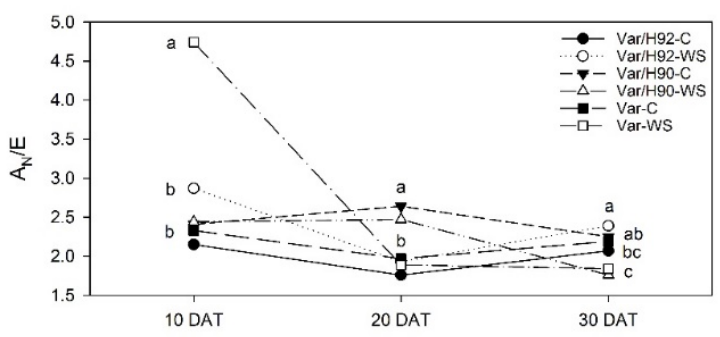

Figure 2. (A) $\mathrm{CO}_{2}$ assimilation rate $\left(\mathrm{A}_{\mathrm{N}}, \mu \mathrm{mol} \mathrm{CO} \mathrm{CO}_{2} \mathrm{~m}^{-2} \mathrm{~s}^{-1}\right)$, (B) stomatal conductance to water vapor $\left(\mathrm{g}_{\mathrm{s}}, \mathrm{mol} \mathrm{H}_{2} \mathrm{O} \mathrm{m}^{-2} \mathrm{~s}^{-1}\right)$, and (C) instantaneous water use efficiency $\left(\mathrm{A}_{\mathrm{N}} / \mathrm{E}\right)$ in the ungrafted plants (Var, variety "Sueca") and Var grafted onto H92 or H90 (Var/H92 and Var/H90, respectively) under the water stress (WS) or control conditions (C). Measurements were taken at 10, 20, and 30 DAT (days after treatment). Data are the mean value for $n=4$ for each plant type and treatment combination. Different letters indicate significant differences at $p<0.05$ (LSD test) for each measurement time separately.

Leaf stomatal conductance $\left(\mathrm{g}_{\mathrm{s}}\right.$, Figure $\left.2 \mathrm{~B}\right)$ reduced in all the plant types during the experiment in the WS treatment compared to the control conditions. Only Var/H92 at 20 DAT did not show any significant differences between the control and stressed plants.

Instantaneous WUE $\left(\mathrm{A}_{\mathrm{N}} / \mathrm{E}\right)$ did not reveal any significant differences at $20 \mathrm{DAT}$ when the control and WS plants were compared for all the plant types (Figure 2C). At 30 DAT, all the plant types showed significant differences between treatments, Var/H92 increased $\mathrm{A}_{\mathrm{N}} / \mathrm{E}$, while $\mathrm{Var} / \mathrm{H} 90$ and Var diminished $\mathrm{A}_{\mathrm{N}} / \mathrm{E}$ under the WS conditions. Var also showed significant differences between treatments at the beginning of the experiment (10 DAT).

\subsection{Ascorbic Acid Metabolism}

For both the evaluated parameters, AsA (reduced ascorbate) and the AsA/AsA $\mathrm{A}_{t}$ ratio, statistically significant interactions $(\mathrm{PT} \times \mathrm{T}$ ) were observed throughout the experiment. 
AsA presented $p<0.01$, while AsA $/$ AsA $_{t}$ showed $p<0.05$ at 10 DAT and $p \leq 0.01$ at 20 DAT and 30 DAT.

At 10 DAT, the AsA values under the WS conditions significantly differed from the C conditions for all the plant types (Figure 3A), with higher Var/H92 and Var/H90 values, and lower Var values. AsA/AsA $A_{t}$ only differed statistically in Var, with a lower ratio under the WS conditions (Figure 3D).
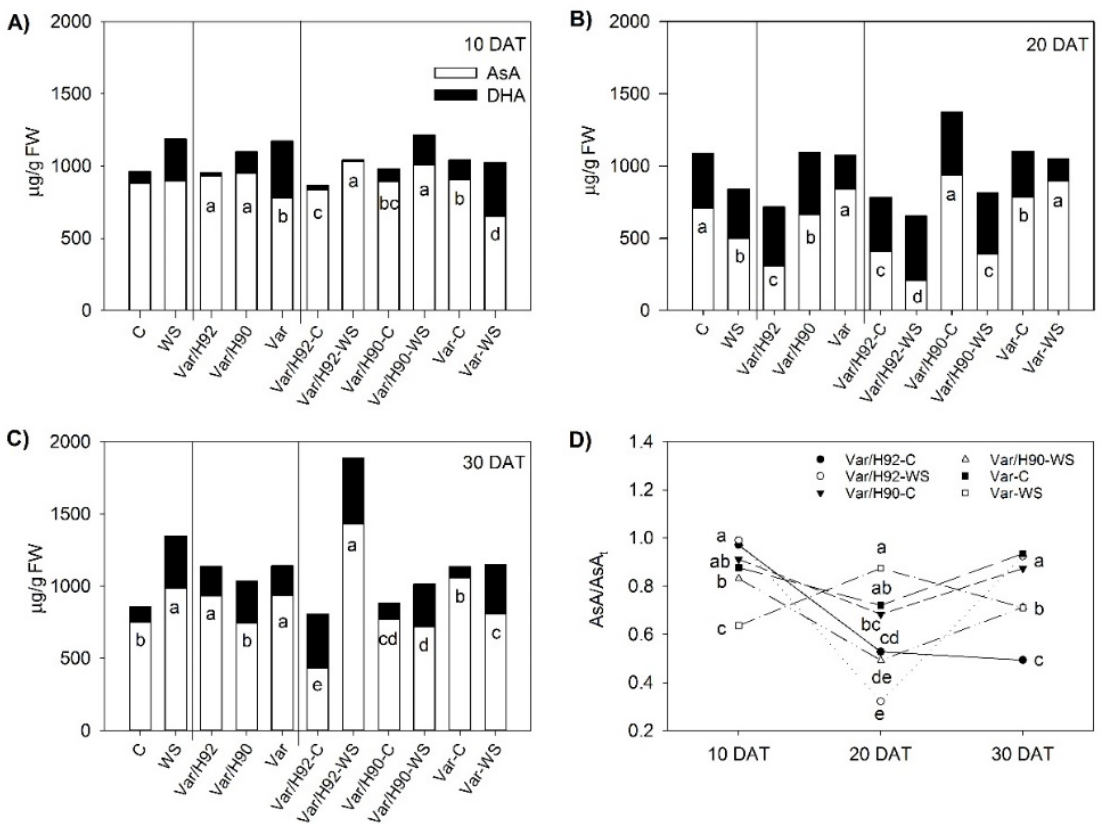

Figure 3. (A-C) Concentration of the different forms of ascorbate (AsA and DHA) in the leaves of the ungrafted plants (Var, variety "Sueca") and Var grafted onto H92 or H90 (Var/H92 and Var/H90) under the water stress (WS) or control conditions (C) at 10, 20, and 30 DAT (days after treatment), respectively. Different letters indicate significant differences at $p<0.05$ (LSD test) for the AsA parameter. No letters in 3A indicate no significant differences. (D) The AsA/AsAt ratio for the aforementioned combinations and time measurements. Different letters indicate significant differences at $p<0.05$ (LSD test) for each measurement time separately. Data are the mean value for $\mathrm{n}=4$ for each plant type and treatment combination.

At 20 DAT, AsA showed significant differences for each plant type between treatments (Figure 3B). Var/H92 and Var/H90 dropped under water starvation, while Var rose.

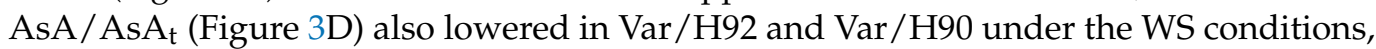
while no significant differences appeared between treatments in Var.

Finally, at $30 \mathrm{DAT}, \mathrm{AsA}$ and AsA/AsA $\mathrm{t}$ presented significant differences between treatments in Var/H92 and Var, whose values grew and fell, respectively, under WS (Figure 3C,D). Var/H90 only displayed differences for AsA/AsA $A_{t}$, which lowered under water starvation compared to the control plants (Figure 3D).

\subsection{Catalase Activity}

For this parameter, statistically significant interactions $(\mathrm{PT} \times \mathrm{T})$ were found during the experiment $(p<0.01)$. All plant types showed significant differences between treatments while testing (Figure $4 \mathrm{~A}-\mathrm{C}$ ). 
A)

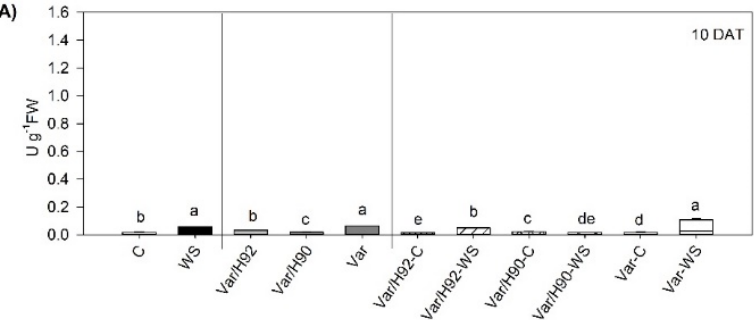

B)

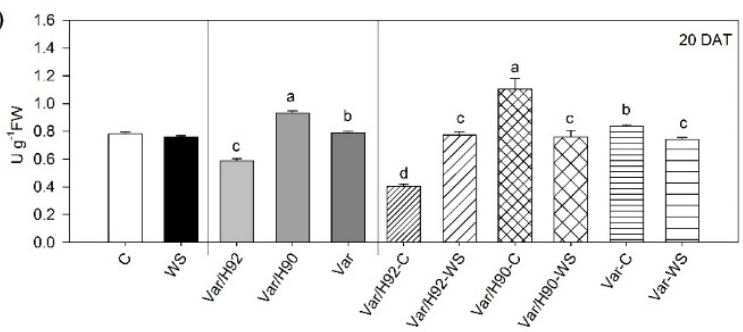

C)

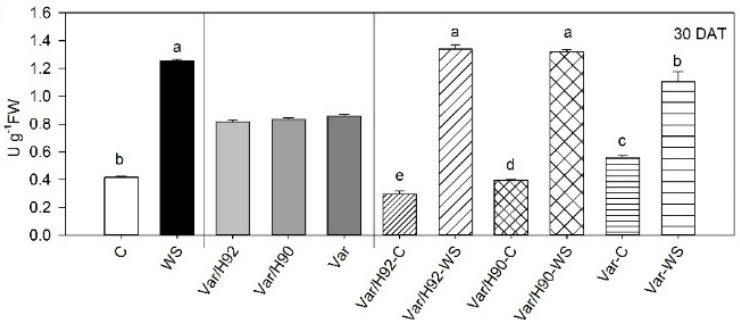

Figure 4. Catalase activity (as $\mathrm{H}_{2} \mathrm{O}_{2}$ reduction, $\mathrm{U} \mathrm{g}^{-1} \mathrm{FW}$ ) in the leaves of the ungrafted plants (Var, variety "Sueca") and Var grafted onto H92 or H90 (Var/H92 and Var/H90) under the water stress (WS) or control conditions (C) at 10 (A), 20 (B), and 30 (C) days after treatment (DAT). Different letters indicate significant differences at $p<0.05$ (LSD test) for each measurement time separately. No letters in (B) an (C) indicate no significant differences. Data are the mean of four replicates and the error bars belong to the standard deviation for each plant type and treatment combination.

Var/H92 significantly increased catalase activity during the experiment under WS (Figure 4A-C). In contrast, Var/H90 only boosted enzyme activity at the end of the experiment (30 DAT) under the water stress conditions, with reduced activity at 10 DAT and 20 DAT (Figure 4A-C). Lastly, Var obtained higher values when WS was applied at 10 DAT and 30 DAT, but lower ones at 20 DAT (Figure 4A-C).

\subsection{Lipid Peroxidation}

Interactions for MDA content $(p<0.01)$ were found between T and PT throughout the experiment. Var/H92 appeared to be undisturbed when subjected to WS all along the experiment. At 10 DAT, only Var showed significant differences and the lowest MDA content for the stress conditions (Figure 5A). At 30 DAT, the MDA content of Var/H90 and Var rose significantly under WS (Figure 5B). 

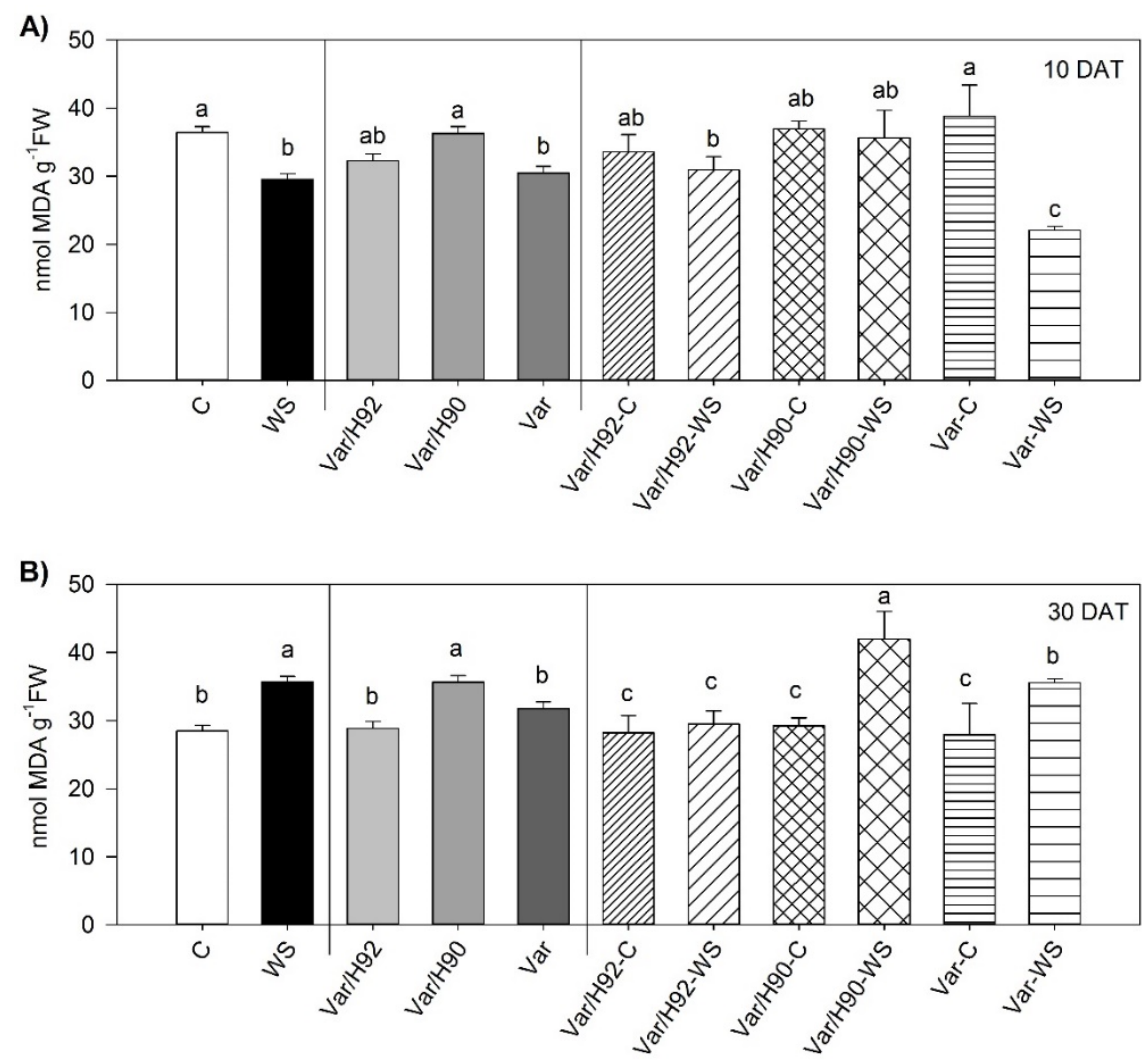

Figure 5. Lipid peroxidation (as malondialdehyde content, MDA) in the leaves of the ungrafted plants (Var, variety "Sueca") and Var grafted onto H92 or H90 (Var/H92 and Var/H90) under the water stress (WS) or control conditions (C) at 10 (A) and 30 (B) days after treatment (DAT). Different letters indicate significant differences at $p<0.05$ (LSD test) for each measurement time separately. Data are the mean of four replicates and the error bars belong to the standard deviation for each plant type and treatment combination.

\subsection{Proline Quantification}

Proline content showed interactions $(p<0.01)$ between PT and T while testing. The whole set of plants had a significantly higher proline content when water stress was applied throughout the experiment (Figure 6A-C). Notwithstanding, more marked increases took place for Var/H90 and Var at 10 DAT (Figure 6A), and also for Var/H92 and Var at 30 DAT (Figure 6B,C). 



Figure 6. Proline content in the leaves of the ungrafted plants (Var, variety "Sueca") and Var grafted onto H92 or H90 (Var/H92 and Var/H90) under the water stress (WS) or control conditions (C) at 10 (A), 20 (B), and 30 (C) days after treatment (DAT). Different letters indicate significant differences at $p<0.05$ (LSD test) for each measurement time separately. Data are the mean of four replicates and the error bars belong to the standard deviation for each plant type and treatment combination.

\subsection{Biomass Determination}

No significant interactions between T and PT were recorded for the measured biomass parameters (fresh and dry weight, leaf area, and number of leaves) (Table 1).

Table 1. Effect of factors treatment $(\mathrm{T})$ and plant type (PT) on the fresh weight (FW) of aerial parts expressed as mean values and ANOVA.

\begin{tabular}{|c|c|c|c|c|c|c|c|c|}
\hline \multirow{3}{*}{ Treatment $(\mathrm{T})$} & \multirow{2}{*}{\multicolumn{2}{|c|}{$\frac{\text { FW }}{\left(\text { g Plant }^{-1}\right)}$}} & \multirow{2}{*}{\multicolumn{2}{|c|}{$\frac{\text { DW }}{\left(\text { g Plant }^{-1}\right)}$}} & \multirow{2}{*}{\multicolumn{2}{|c|}{$\begin{array}{c}\text { Leaf Area } \\
\left(\mathrm{cm}^{2}\right)\end{array}$}} & \multirow{2}{*}{\multicolumn{2}{|c|}{ Number of Leaves }} \\
\hline & & & & & & & & \\
\hline & & & & & & & & \\
\hline C & 335.3 & a & 50.27 & $\mathrm{a}$ & 6095 & a & 161.7 & a \\
\hline WS & 191.4 & $\mathrm{~b}$ & 28.88 & $\mathrm{~b}$ & 3602 & $\mathrm{~b}$ & 138.9 & $\mathrm{~b}$ \\
\hline \multicolumn{9}{|l|}{ Plant Type (PT) } \\
\hline Var/H92 & 277.6 & a & 41.15 & & 5265 & a & 153.4 & \\
\hline Var/H90 & 267.6 & $\mathrm{ab}$ & 36.48 & & 4469 & $\mathrm{~b}$ & 143.3 & \\
\hline Var & 244.9 & $\mathrm{~b}$ & 41.09 & & 4812 & $a b$ & 154.3 & \\
\hline ANOVA $(d f)$ & \multicolumn{8}{|c|}{$\%$ Sum of Squares } \\
\hline $\mathrm{T}(1)$ & 82.36 & $* *$ & 76.94 & ** & 77.12 & $* *$ & 17.89 & $* *$ \\
\hline $\mathrm{PT}(2)$ & 3.04 & $*$ & 3.41 & & 5.27 & * & 3.56 & \\
\hline $\mathrm{T} \times \mathrm{PT}(2)$ & 2.09 & & 1.64 & & 4.45 & & 10.07 & \\
\hline Residuals (30) & 12.51 & & 18.01 & & 13.16 & & 68.48 & \\
\hline Standard Deviation ${ }^{(+)}$ & 30.6 & & 5.64 & & 594 & & 24.3 & \\
\hline
\end{tabular}

Different letters following the mean values indicate significant differences at $p<0.05$ with the LSD test. An asterisk *indicates significant differences at $p<0.05$ with the LSD test, while two asterisks ${ }^{* *}$ indicate significant differences at $p \leq 0.01 .{ }^{(+)}$Calculated as the square root of the residual sum of squares. $d f$ degrees of freedom. 
The fresh weight of the plant aerial parts showed significant differences for both $\mathrm{T}$ and PT, with $p<0.01$ and $p<0.05$, respectively (Table 1). Aerial fresh weight reduced by $43 \%$ in the stressed plants vs. the control ones. The highest FW mean PT value was for Var/H92, followed by Var/H90 and Var (Table 1).

For the dry weight of plant aerial parts, only $\mathrm{T}$ exhibited significant differences with $p<0.01$. The plants under water stress had lower dry weight values than those under the control conditions (Table 1).

Leaf area exhibited significant differences for T and PT, with $p<0.01$ and $p<0.05$, respectively. Stressed plants reduced leaf area vs. the control plants. For PT, the biggest leaf area was for Var/H92, followed by Var and Var/H90 (Table 1).

Significant differences were recorded only for number of leaves for $\mathrm{T}(p<0.01)$. The plants under water stress had a smaller number of leaves than the plants under the control conditions (Table 1).

\section{Discussion}

As expected, leaf RWC decreased under WS in all PT, but the highest reduction was in Var (22\%) following Var/H90 (16\%) and Var/H92 (12\%), which showed the better RWC conservation. According to Hsiao [48], the decrease in RWC might indicate that Var/H90 and Var/H92 suffered a moderate WS while Var was affected by severe WS. The greater RWC in Var/H92 indicated higher capacity of water retention [49]. To maintain water uptake under the osmotic stress provoked by water scarcity, plants tend to decrease leaf $\Psi$ s. In our conditions, under WS, a fall in leaf $\Psi$ s was observed in all PT, and $\Psi$ s decrease was not enough to maintain RWC mainly in Var and Var/H90 plants. This drop in Is could be a consequence of a reduction in the leaf water content (dehydration) and/or due to active solute accumulation. Free proline is one of the most important osmolytes whose accumulation provokes a fall in $\Psi$ s [50]. Nevertheless, in our experimental conditions, the proline role contributing to lower $\Psi$ s was negligible, with mean values of $0.015 \mathrm{MPa}$ and a $1.1 \%$ of contribution to $\Psi \mathrm{s}$, without ruling out that other components can be implicated in the reduction of osmotic potential [51].

Alterations in water relations under WS affected photosynthesis process in all PT. However, differential behavior was observed among them. After $10 \mathrm{DAT}, \mathrm{A}_{\mathrm{N}}$ decreased in Var/H90 and Var, but not in Var/H92, which showed no significant differences with control plants. At the end of the experiment, $\mathrm{A}_{\mathrm{N}}$ significantly decreased in all PT respect to their control, despite Var/H92 got the highest values under WS. These results agree with the ones obtained in grafted plants using tolerant rootstocks, which improved photosynthesis under WS (see reviews in $[5,12]$ ). In our experiment, the decrease in $\mathrm{A}_{\mathrm{N}}$ showed linear correlation $(p<0.0001)$ with gs in all PT at 10, 20 and 30 DAT $(r=0.886,0.742$ and 0.937 , respectively), which could mean that $\mathrm{A}_{\mathrm{N}}$ reduction was mainly due to stomata limitations $[25,30]$.

Grafting has been identified as an effective tool for increasing WUE in water stress situations [13,27]. A significant increase in WUE under water stress took place in Var/H92 at the end of experiment compared to the other PTs, which could result from the improvement in $\mathrm{CO}_{2}$ assimilation rate and the amelioration of stomata performance. In Var and Var/H90 in response to water stress, higher RWC reduction and $\Psi$ s can be related with stomatal closure and lower WUE, according to [52]. This result suggests fewer water requirements in Var/H92 combination, which is interesting because its water use should be lower. Similar results have been obtained by López-Marín et al., [17] in pepper plants grafted onto the "Terrano" rootstock, in cucumber grafted onto luffa [24] or in mini-watermelon grafted onto Cucurbita maxima $\times$ C. moschata [25]. It is noteworthy that our results showed how H92 rootstock could influence the scion-plant response to water stress in photosynthesis, stomatal conductance and WUE terms, which suggests that this plant combination performs better under water stress in gas exchange terms.

Despite the benefits of vegetable grafting on photosynthesis maintenance, and the antioxidant system role under water stress are both widely described in the scientific bibliography $[5,12,53]$, few research has established a link between both plant mechanisms, 
especially in pepper grafted plants. Indeed, enhanced proline biosynthesis and proline degradation inactivation have been described to be involved in sustaining the electron flow between both photosystems by reducing photoinhibition and protecting the photosynthetic apparatus [54-56]. Accumulated proline also acts as a low-molecular-weight cellular antioxidant that protects plants from WS [57]. An improvement in proline accumulation under WS has been observed in grafted plants compared to ungrafted plants, and has been demonstrated in pepper [16] or tomato plants [49]. The increase in proline could be related to its protective role acting as a free radical scavenger, and also protecting thylakoids membrane and photosynthetic activity [56]; as it plays an important role in overcoming abiotic stress $[50,56]$. Indeed, a significant negative linear correlation between $\mathrm{A}_{\mathrm{N}}$ and proline concentration $(p<0.01)$ was measured at $10 \mathrm{DAT}, 20 \mathrm{DAT}$, and 30 DAT $\left(\mathrm{r}=-0.65,-0.72\right.$, and -0.52 , respectively). This implies that while $\mathrm{A}_{\mathrm{N}}$ decreased, proline increased with the same trend. This relation constituted a coupled response to water stress by minimizing its impact on plant performance, and it has been observed in peppergrafted plants under salt stress [58] and sunflower [59]. The highest proline concentration herein observed was detected in Var/H92 and Var under WS from 20 DAT to 30 DAT. Nevertheless, a significantly lower photosynthesis rate was observed for the Var plants under WS, similarly to the Var/H90 plants. This finding indicates that other processes or antioxidant molecules apart from proline can be activated in Var/H92 plants to sustain photosynthesis under stress. A positive linear correlation $(p<0.01)$ was found at 10 and 30 DAT between $A_{N}$ and AsA $/ A_{s} A_{t}(r=0.84$ for 10 DAT and $r=0.55$ for 30 DAT). Indeed, a marked significant increase in AsA and the AsA/AsA $\mathrm{A}_{t}$ ratio was measured in Var/H92 at the end of experiment, when WS pressure on plants was higher. Higher AsA levels have been observed in tolerant tomato- and pepper-grafted plants under both salinity and water stress $[8,60,61]$. With stress, AsA is involved in protecting against ROS and photooxidative stress, that linked with sustained photosynthesis provides protection through the zeaxanthin interaction and subsequent thermal dissipation regulation [62,63]. No AsA increase was observed in the Var/H90 and Var plants under WS at 30 DAT.

Plants under water stress overproduce ROS, one of them is $\mathrm{H}_{2} \mathrm{O}_{2}$, which is detoxified by catalase enzyme [64]. In our conditions, catalase activity significantly increased in all PT in response to WS, mainly at the end of the experiment. This increase was not consistent with the changes in lipid peroxidation, given that an important increase in lipid peroxidation was measured in Var/H90 and Var, but not in Var/H92. These results can indicate that other types of ROS could be implicated in the MDA production in Var and Var/H90, and the catalase activity was enough to eliminate $\mathrm{H}_{2} \mathrm{O}_{2}$ in Var/H92.

Water-limiting conditions result in impaired growth, and reduce both the number of leaves and individual leaf size [65]. According to our results obtained under water stress, the fresh and dry weights of aerial plant parts, leaf area, and number of leaves decreased in all the plants respect to control conditions. In addition, DW values in aerial part did not show any significant differences between PT, probably because root biomass, which could be significant for total biomass, has not been quantified as the culture characteristics of potted plants with substrate made it difficult to obtain roots.

Nonetheless, FW considering PT factor was higher in the Var/H92 plants, associated with higher water conservation or acquisition capacity. Leaf expansion normally depends on turgor pressure and assimilates supply. Thus, slow $\mathrm{CO}_{2}$ fixation could limit this process in Var/H90 and Var, and to a lesser extent in Var/H92 [65]. Nevertheless, our biomass values reflected the performance of whole plant net photosynthesis throughout the growth period, and not through the effect on the instantaneous net assimilation rate of $\mathrm{CO}_{2}$ by single-leaf measurements.

\section{Conclusions}

In conclusion, the higher maintained rate of $\mathrm{CO}_{2}$ uptake observed using the tolerant rootstock $\mathrm{H} 92$ seems to involve minor oxidative stress, as observed by lesser membrane lipid peroxidation related to higher proline content and AsA concentration. Nonetheless, 
to validate these results, rootstock $\mathrm{H} 92$ should be tested under long-term experiments to evaluate its effects in terms of productivity and biomass under water stress.

Author Contributions: Conceptualization, S.L.-G. and Á.C.; methodology, S.L.-G., Á.C., R.G.-M., Y.G.P., and L.L.-S.; validation, R.G.-M., Á.C., S.L.-G., Y.G.P., and L.L.-S.; formal Analysis, R.G.-M. and Y.G.P.; research, R.G.-M., Á.C., Y.G.P., and L.L.-S.; resources, S.L.-G. and Á.C.; data curation, R.G.-M., Y.G.P., L.L.-S., and Á.C.; writing-original draft preparation, S.L.-G., Á.C., and Y.G.P.; writing-review and editing, S.L.-G., Á.C., and Y.G.P.; visualization, R.G.-M., Á.C., S.L.-G., Y.G.P., and L.L.-S.; supervision, Y.G.P., S.L.-G., and Á.C.; project administration, S.L.-G. and Á.C. All authors have read and agreed to the published version of the manuscript.

Funding: This work has been financed by the INIA (Spain) and the Ministerio de Ciencia, Innovación y Universidades through Project RTA-2017-00030-C02 and the European Regional Development Fund (ERDF). R.G.-M. is a beneficiary of a doctoral fellowship (FPU-MEFP (Spain)). Y.G.P. is a beneficiary of a doctoral fellowship (FPI-INIA (Spain)).

Institutional Review Board Statement: Not applicable.

Informed Consent Statement: Not applicable.

Data Availability Statement: The data presented in this study are available in the graphs and table provided in the manuscript.

Conflicts of Interest: The authors declare no conflict of interest.

\section{References}

1. Sah, S.K.; Reddy, K.R.; Li, J. Abscisic acid and abiotic stress tolerance in crop plants. Front. Plant Sci. 2016, 7, 571. [CrossRef]

2. Athar, H.R.; Ashraf, M. Strategies for Crop Improvement Against Salinity and Drought Stress: An Overview. In Salinity and Water Stress; Springer: Dordrecht, The Netherlands, 2009; pp. 1-16. ISBN 978-1-4020-9065-3.

3. Wang, W.; Vinocur, B.; Altman, A. Plant responses to drought, salinity and extreme temperatures: Towards genetic engineering for stress tolerance. Planta 2003, 218, 1-14. [CrossRef] [PubMed]

4. Ashraf, M. Inducing drought tolerance in plants: Recent advances. Biotechnol. Adv. 2010, 28, 169-183. [CrossRef] [PubMed]

5. Kumar, P.; Rouphael, Y.; Cardarelli, M.; Colla, G. Vegetable Grafting as a Tool to Improve Drought Resistance and Water Use Efficiency. Front. Plant Sci. 2017, 8, 1130. [CrossRef] [PubMed]

6. Mastrangelo, A.M.; Mazzucotelli, E.; Guerra, D.; De Vita, P.; Cattivelli, L. Improvement of drought resistance in crops: From conventional breeding to genomic selection. In Crop Stress and Its Management: Perspectives and Strategies; Springer: Dordrecht, The Netherlands, 2012; pp. 225-259. ISBN 9789400722200.

7. Farooq, M.; Wahid, A.; Kobayashi, N.; Fujita, D.; Basra, S.M.A. Plant drought stress: Effects, mechanisms and management. Agron. Sustain. Dev. 2009, 29, 185-212. [CrossRef]

8. Sánchez-Rodríguez, E.; del Rubio-Wilhelmi, M.; Blasco, B.; Leyva, R.; Romero, L.; Ruiz, J.M. Antioxidant response resides in the shoot in reciprocal grafts of drought-tolerant and drought-sensitive cultivars in tomato under water stress. Plant Sci. 2012, 188-189, 89-96. [CrossRef] [PubMed]

9. Bourzac, K. Water: The flow of technology. Nature 2013, 501, S4-S6. [CrossRef]

10. Eisenstein, M. Plant breeding: Discovery in a dry spell. Nature 2013, 501. [CrossRef]

11. Rouphael, Y.; Kyriacou, M.C.; Colla, G. Vegetable Grafting: A Toolbox for Securing Yield Stability under Multiple Stress Conditions. Front. Plant Sci. 2018, 8, 2255. [CrossRef]

12. Schwarz, D.; Rouphael, Y.; Colla, G.; Venema, J.H. Grafting as a tool to improve tolerance of vegetables to abiotic stresses: Thermal stress, water stress and organic pollutants. Sci. Hortic. 2010, 127, 162-171. [CrossRef]

13. Fullana-Pericàs, M.; Conesa, M.; Pérez-Alfocea, F.; Galmés, J. The influence of grafting on crops' photosynthetic performance. Plant Sci. 2020, 295, 110250. [CrossRef]

14. Goldschmidt, E.E. Plant grafting: New mechanisms, evolutionary implications. Front. Plant Sci. 2014, 5, 727. [CrossRef] [PubMed]

15. Koevoets, I.T.; Venema, J.H.; Elzenga, J.T.M.; Testerink, C. Roots withstanding their environment: Exploiting root system architecture responses to abiotic stress to improve crop tolerance. Front. Plant Sci. 2016, 7, 1335. [CrossRef]

16. Penella, C.; Nebauer, S.G.; Bautista, A.S.; López-Galarza, S.; Calatayud, Á. Rootstock alleviates PEG-induced water stress in grafted pepper seedlings: Physiological responses. J. Plant Physiol. 2014, 171, 842-851. [CrossRef] [PubMed]

17. López-Marín, J.; Gálvez, A.; del Amor, F.M.; Albacete, A.; Fernández, J.A.; Egea-Gilabert, C.; Pérez-Alfocea, F. Selecting vegetative/generative/dwarfing rootstocks for improving fruit yield and quality in water stressed sweet peppers. Sci. Hortic. 2017, 214, 9-17. [CrossRef]

18. López-Serrano, L.; Canet-Sanchis, G.; Vuletin Selak, G.; Penella, C.; San Bautista, A.; López-Galarza, S.; Calatayud, Á. Pepper Rootstock and Scion Physiological Responses Under Drought Stress. Front. Plant Sci. 2019, 10, 38. [CrossRef] 
19. Zhang, Z.; Cao, B.; Gao, S.; Xu, K. Grafting improves tomato drought tolerance through enhancing photosynthetic capacity and reducing ROS accumulation. Protoplasma 2019, 256, 1013-1024. [CrossRef]

20. Penella, C.; Nebauer, S.G.; López-Galarza, S.; Quiñones, A.; San Bautista, A.; Calatayud, Á. Grafting pepper onto tolerant rootstocks: An environmental-friendly technique overcome water and salt stress. Sci. Hortic. 2017, 226, 33-41. [CrossRef]

21. Chaves, M.M. Effects of Water Deficits on Carbon Assimilation. J. Exp. Bot. 1991, 42, 1-16. [CrossRef]

22. Flexas, J.; Bota, J.; Cifre, J.; Escalona, J.; Galmes, J.; Gulias, J.; Lefi, E.-K.; Martinez-Canellas, S.; Moreno, M.; Ribas-Carbo, M.; et al. Understanding down-regulation of photosynthesis under water stress: Future prospects and searching for physiological tools for irrigation management. Ann. Appl. Biol. 2004, 144, 273-283. [CrossRef]

23. Khah, E.M.; Katsoulas, N.; Tchamitchian, M.; Kittas, C. Effect of grafting on eggplant leaf gas exchanges under mediterranean greenhouse conditions. Int. J. Plant Prod. 2011, 5, 121-134.

24. Liu, S.; Li, H.; Lv, X.; Ahammed, G.J.; Xia, X.; Zhou, J.; Shi, K.; Asami, T.; Yu, J.; Zhou, Y. Grafting cucumber onto luffa improves drought tolerance by increasing ABA biosynthesis and sensitivity. Sci. Rep. 2016, 6, 1-14. [CrossRef] [PubMed]

25. Rouphael, Y.; Cardarelli, M.; Colla, G.; Rea, E. Yield, mineral composition, water relations, and water use efficiency of grafted mini-watermelon plants under deficit irrigation. HortScience 2008, 43, 730-736. [CrossRef]

26. Fullana-Pericàs, M.; Ponce, J.; Conesa, M.; Juan, A.; Ribas-Carbó, M.; Galmés, J. Changes in yield, growth and photosynthesis in a drought-adapted Mediterranean tomato landrace (Solanum lycopersicum 'Ramellet') when grafted onto commercial rootstocks and Solanum pimpinellifolium. Sci. Hortic. 2018, 233, 70-77. [CrossRef]

27. Fullana-Pericàs, M.; Conesa, M.À.; Ribas-Carbó, M.; Galmés, J. The Use of a Tomato Landrace as Rootstock Improves the Response of Commercial Tomato under Water Deficit Conditions. Agronomy 2020, 10, 748. [CrossRef]

28. Galmés, J.; Conesa, M.À.; Ochogavía, J.M.; Perdomo, J.A.; Francis, D.M.; Ribas-Carbó, M.; Savé, R.; Flexas, J.; Medrano, H.; Cifre, J. Physiological and morphological adaptations in relation to water use efficiency in Mediterranean accessions of Solanum lycopersicum. Plant. Cell Environ. 2011, 34, 245-260. [CrossRef] [PubMed]

29. Galmés, J.; Ochogavía, J.M.; Gago, J.; Roldán, E.J.; Cifre, J.; Conesa, M.À. Leaf responses to drought stress in Mediterranean accessions of Solanum lycopersicum: Anatomical adaptations in relation to gas exchange parameters. Plant. Cell Environ. 2013, 36, 920-935. [CrossRef]

30. Delfine, S.; Tognetti, R.; Loreto, F.; Alvino, A. Physiological and growth responses to water stress in field-grown bell pepper (Capsicum annuum L.). J. Hortic. Sci. Biotechnol. 2002, 77, 697-704. [CrossRef]

31. Zhou, Y.; Zhou, J.; Huang, L.; Ding, X.; Shi, K.; Yu, J. Grafting of Cucumis sativus onto Cucurbita ficifolia leads to improved plant growth, increased light utilization and reduced accumulation of reactive oxygen species in chilled plants. J. Plant Res. 2009, 122, 529-540. [CrossRef]

32. Pinheiro, H.A.; DaMatta, F.M.; Chaves, A.R.M.; Fontes, E.P.B.; Loureiro, M.E. Drought tolerance in relation to protection against oxidative stress in clones of Coffea canephora subjected to long-term drought. Plant Sci. 2004, 167, 1307-1314. [CrossRef]

33. Blokhina, O. Antioxidants, Oxidative Damage and Oxygen Deprivation Stress: A Review. Ann. Bot. 2003, 91, 179-194. [CrossRef]

34. Apel, K.; Hirt, H. Reactive Oxygen Species: Metabolism, Oxidative Stress, and Signal Transduction. Annu. Rev. Plant Biol. 2004, 55, 373-399. [CrossRef]

35. Foyer, C.H.; Halliwell, B. The presence of glutathione and glutathione reductase in chloroplasts: A proposed role in ascorbic acid metabolism. Planta 1976, 133, 21-25. [CrossRef] [PubMed]

36. Kaur, K.; Kaur, N.; Gupta, A.K.; Singh, I. Exploration of the antioxidative defense system to characterize chickpea genotypes showing differential response towards water deficit conditions. Plant Growth Regul. 2013, 70, 49-60. [CrossRef]

37. Lee, J.M.; Kubota, C.; Tsao, S.J.; Bie, Z.; Echevarria, P.H.; Morra, L.; Oda, M. Current status of vegetable grafting: Diffusion, grafting techniques, automation. Sci. Hortic. 2010, 127, 93-105. [CrossRef]

38. Kyriacou, M.C.; Rouphael, Y.; Colla, G.; Zrenner, R.; Schwarz, D. Vegetable grafting: The implications of a growing agronomic imperative for vegetable fruit quality and nutritive value. Front. Plant Sci. 2017, 8, 741. [CrossRef]

39. Penella, C.; Nebauer, S.G.; Lopéz-Galarza, S.; San Bautista, A.; Gorbe, E.; Calatayud, A. Evaluation for salt stress tolerance of pepper genotypes to be used as rootstocks. J. Food Agric. Environ. 2013, 11, 1101-1107.

40. Penella, C.; Nebauer, S.G.; López-Galarza, S.; San Bautista, A.; Rodríguez-Burruezo, A.; Calatayud, A. Evaluation of some pepper genotypes as rootstocks in water stress conditions. Hortic. Sci. 2014, 41, 192-200. [CrossRef]

41. López-Serrano, L.; Penella, C.; San-Bautista, A.; López-Galarza, S.; Calatayud, A. Physiological changes of pepper accessions in response to salinity and water stress. Span. J. Agric. Res. 2017, 15, 1-10. [CrossRef]

42. Maynard, D.N.; Hochmuth, G.J. Knott's Handbook for Vegetable Growers, 5th ed.; John Wiley \& Sons Inc: Hoboken, NJ, USA, 2006; ISBN 9780470121474.

43. Kampfenkel, K.; Vanmontagu, M.; Inze, D. Extraction and Determination of Ascorbate and Dehydroascorbate from Plant Tissue. Anal. Biochem. 1995, 225, 165-167. [CrossRef] [PubMed]

44. Martinez-Cuenca, M.-R.; Primo-Capella, A.; Quiñones, A.; Bermejo, A.; Forner-Giner, M.A. Rootstock influence on iron uptake responses in Citrus leaves and their regulation under the Fe paradox effect. PeerJ 2017, 5, e3553. [CrossRef]

45. Heath, R.L.; Packer, L. Photoperoxidation in isolated chloroplasts. Arch. Biochem. Biophys. 1968, 125, 189-198. [CrossRef]

46. Dhindsa, R.S.; Plumb-Dhindsa, P.; Thorpe, T.A. Leaf Senescence: Correlated with Increased Levels of Membrane Permeability and Lipid Peroxidation, and Decreased Levels of Superoxide Dismutase and Catalase. J. Exp. Bot. 1981, 32, 93-101. [CrossRef] 
47. Bates, L.S.; Waldren, R.P.; Teare, I.D. Rapid determination of free proline for water-stress studies. Plant Soil 1973, 39, $205-207$. [CrossRef]

48. Hsiao, T.C. Plant Responses to Water Stress. Annu. Rev. Plant Physiol. 1973, 24, 519-570. [CrossRef]

49. Yao, X.; Yang, R.; Zhao, F.; Wang, S.; Li, C.; Zhao, W. An analysis of physiological index of differences in drought tolerance of tomato rootstock seedlings. J. Plant Biol. 2016, 59, 311-321. [CrossRef]

50. Gill, S.S.; Tuteja, N. Reactive oxygen species and antioxidant machinery in abiotic stress tolerance in crop plants. Plant Physiol. Biochem. 2010, 48, 909-930. [CrossRef] [PubMed]

51. Navarro, J.M.; Garrido, C.; Martínez, V.; Carvajal, M. Water relations and xylem transport of nutrients in pepper plants grown under two different salts stress regimes. Plant Growth Regul. 2003, 41, 237-245. [CrossRef]

52. Gaion, L.A.; Monteiro, C.C.; Cruz, F.J.R.; Rossatto, D.R.; López-Díaz, I.; Carrera, E.; Lima, J.E.; Peres, L.E.P.; Carvalho, R.F. Constitutive gibberellin response in grafted tomato modulates root-to-shoot signaling under drought stress. J. Plant Physiol. 2018, 221, 11-21. [CrossRef]

53. Rivero, R.M.; Ruiz, J.; Romero, L. Role of grafting in horticultural plants under stress conditions. J. Food Agric. Environ. 2003, 1, 70-74.

54. Szabados, L.; Savouré, A. Proline: A multifunctional amino acid. Trends Plant Sci. 2010, 15, 89-97. [CrossRef] [PubMed]

55. Ashraf, M.; Foolad, M.R. Roles of glycine betaine and proline in improving plant abiotic stress resistance. Environ. Exp. Bot. 2007, 59, 206-216. [CrossRef]

56. Reddy, A.R.; Chaitanya, K.V.; Vivekanandan, M. Drought-induced responses of photosynthesis and antioxidant metabolism in higher plants. J. Plant Physiol. 2004, 161, 1189-1202. [CrossRef]

57. Anjum, S.A.; Farooq, M.; Xie, X.-Y.; Liu, X.-J.; Ijaz, M.F. Antioxidant defense system and proline accumulation enables hot pepper to perform better under drought. Sci. Hortic. 2012, 140, 66-73. [CrossRef]

58. Penella, C.; Nebauer, S.G.; Quiñones, A.; San Bautista, A.; López-Galarza, S.; Calatayud, A. Some rootstocks improve pepper tolerance to mild salinity through ionic regulation. Plant Sci. 2015, 230, 12-22. [CrossRef]

59. Ghobadi, M.; Taherabadi, S.; Ghobadi, M.E.; Mohammadi, G.R.; Jalali-Honarmand, S. Antioxidant capacity, photosynthetic characteristics and water relations of sunflower (Helianthus annuus L.) cultivars in response to drought stress. Ind. Crops Prod. 2013, 50, 29-38. [CrossRef]

60. He, Y.; Zhu, Z.; Yang, J.; Ni, X.; Zhu, B. Grafting increases the salt tolerance of tomato by improvement of photosynthesis and enhancement of antioxidant enzymes activity. Environ. Exp. Bot. 2009, 66, 270-278. [CrossRef]

61. Penella, C.; Landi, M.; Guidi, L.; Nebauer, S.G.; Pellegrini, E.; Bautista, A.S.; Remorini, D.; Nali, C.; López-Galarza, S.; Calatayud, A. Salt-tolerant rootstock increases yield of pepper under salinity through maintenance of photosynthetic performance and sinks strength. J. Plant Physiol. 2016, 193, 1-11. [CrossRef] [PubMed]

62. Foyer, C.H. Redox homeostasis: Opening up ascorbate transport. Nat. Plants 2015, 1, 1-2. [CrossRef]

63. Horton, P.; Ruban, A. Molecular design of the photosystem II light-harvesting antenna: Photosynthesis and photoprotection. J. Exp. Bot. 2004, 56, 365-373. [CrossRef] [PubMed]

64. Hasanuzzaman, M.; Bhuyan, M.H.M.B.; Zulfiqar, F.; Raza, A.; Mohsin, S.M.; Mahmud, J.A.; Fujita, M.; Fotopoulos, V. Reactive Oxygen Species and Antioxidant Defense in Plants under Abiotic Stress: Revisiting the Crucial Role of a Universal Defense Regulator. Antioxidants 2020, 9, 681. [CrossRef] [PubMed]

65. Fahad, S.; Bajwa, A.; Anjum, S.A. Crop Production under Drought and Heat Stress: Plant Responses and Management Options. Front. Plant Sci. 2017, 8, 1147. [CrossRef] [PubMed] 